\title{
Studies on exercise physiology and performance testing of racehorses performed in Japan during the 1930s using recovery rate as an index
}

\author{
Atsushi HIRAGA ${ }^{*}$ and Shigeru SUGANO ${ }^{2}$ \\ ${ }^{1}$ Hidaka Training and Research Center of Japan Racing Association, Hokkaido 057-0171, Japan \\ ${ }^{2}$ Professor Emeritus, The University of Tokyo, Tokyo 180-0004, Japan
}

The history of research on the exercise physiology of racehorses in Japan dates back to the 1930s. A research report entitled "Studies on exercise physiology and performance testing of the racehorse", published in 1933 by Shigeo Matsuba and Torao Shimamura of The University of Tokyo, was epoch-making and the most important study in the history of equine exercise physiology in Japan. Research results were reported from 92 Thoroughbred racehorses in a large-scale project during the period of 1928 to 1932 at the Shimofusa Imperial Farm and the Koiwai Farm, which were the two greatest racehorse farms at that time. A total of 20 physiological variables were measured to evaluate the fitness of Thoroughbred racehorses before exercise (Pre), just after exercise (Post), $1 \mathrm{hr}$ after exercise (1 hr), $2 \mathrm{hr}$ after exercise ( $2 \mathrm{hr}$ ), and $3 \mathrm{hr}$ after exercise ( $3 \mathrm{hr}$ ) in order to calculate their recovery rates as an index of fitness and performance. The percentage of the Pre value at $1 \mathrm{hr}, 2 \mathrm{hr}$, and $3 \mathrm{hr}$ was calculated. When the percentage of a variable reached 95-105\% of the Pre value, the variable was considered to be recovered. The percentage of the total number of variables that were recovered for each time period was calculated, and an overall average was calculated from them; Matsuba and Shimamura proposed calling this overall average the "recovery rate", which could then be applied to evaluate each horse. The effects of training on racehorses were subsequently evaluated by measuring the various physiological variables and the recovery rate.

Key words: equine exercise physiology, performance testing, racehorse, recovery rate, training

\author{
J. Equine Sci. \\ Vol. 27, No. 4 \\ pp. 131-142, 2016
}

The history of research on the exercise physiology of the horse in Japan dates back to the 1920s when warhorses were important. In 1930, a special issue of Rikugun Juidanho (Research Reports of the Japanese Army Veterinary Corps) on the exercise physiology of the warhorse, for which Sawayama played a major role as editor, was published [44]. This special issue mainly dealt with exercise physiology of endurance riding and draft work of the warhorse, and was comprised of general remarks making up 4 chapters,

Received: May 26, 2016

Accepted: September 29, 2016

*Corresponding author. e-mail: hiraga@equinst.go.jp

(C)2016 Japanese Society of Equine Science

This is an open-access article distributed under the terms of the Creative Commons Attribution Non-Commercial No Derivatives (by-nc-nd) License $<$ http://creativecommons.org/licenses/by-nc-nd/4.0/>.
1) objectives of exercise physiology, 2) the horse and exercise, 3 ) the physiological essence of exercise, and 4) types of exercise, followed by detailed information in 11 chapters, 1) exercise physiology of the blood, 2) exercise physiology of the circulatory system, 3) exercise physiology of the respiratory system, 4) exercise physiology of the digestive system, 5) exercise physiology of the skeletal system, 6) exercise physiology of joints, 7) exercise physiology of muscle, 8) effect of exercise on body temperature, 9) effect of exercise on the skin, 10) effect of exercise on the urinary system, and 11) fatigue.

After this issue was published, papers on exercise physiology of the warhorse written by the research group in which Yasuda played a key role appeared in Rikugun Juidanho [30, 38, 51] and other veterinary journals, such as Chuo Juigaku Zasshi (Journal of the Central Society for Veterinary Medicine; the current Journal of Veterinary 
Medical Science) [7, 8, 52]. Because a major shift from the use of warhorses to the use of draft horses occurred after World War II, research on the exercise physiology of draft horses was intensively performed during the period of $1950 \mathrm{~s}$ to 1960 s $[9,29,36,46-48]$.

In terms of studies on the exercise physiology of the racehorse, a research report entitled "Studies on exercise physiology and performance testing of the racehorse", published in 1933 by Shigeo Matsuba and Torao Shimamura of The University of Tokyo [19], was epoch-making and the most important study in the history of equine exercise physiology in Japan. This study measured a total of 20 physiological variables before exercise, just after exercise, and during the recovery process after exercise in order to evaluate the fitness and performance of Thoroughbred racehorses by calculating their recovery rate. Sawazaki of The University of Tokyo stated in his review of the equine science pioneers in Japan that the presentation by Matsuba on exercise physiology of the racehorse and the concept of the recovery rate that was presented at the international conference of physiology held in Moscow in 1930 attracted worldwide attention [45]. After publication of the report of Matsuba and Shimamura, the number of papers on the exercise physiology of racehorses began increasing in journals.

In addition, the studies of Matsuba and Shimamura had great impact on exercise physiology studies of warhorses as well as those of racehorses. In 1942, Ogura of the Imperial University of Taipei (now defunct) published a 100-page report entitled "Performance testing of the horse [31]", concerning a study of warhorses. He measured similar variables as in the studies of Matsuba and Shimamura during three different types of experiments - running, carriage, and draft experiments - and calculated a new performance index to evaluate the performance of the warhorse. He mentioned that if there had been no study by Matsuba and Shimamura $[19,25]$, he would not have performed the study.

Although some of the contents of these studies carried out during the 1930s might be considered old-fashioned from the viewpoint of current knowledge of exercise physiology, it is valuable to remember the contributions of these studies to the discipline and not allow them to be forgotten.

\section{Exercise Physiology of the Racehorse}

Matsuba and Shimamura's report on the exercise physiology and performance testing of racehorses (Fig. 1) was a large book of 294 pages (B5 size) consisting of 2 parts; the first part was entitled "Exercise physiology of the racehorse", and the second part was entitled "Performance testing of the racehorse". Research results obtained from a large-scale project during the period of 1928 to 1932 , which was conducted at the Shimofusa Imperial Farm and the

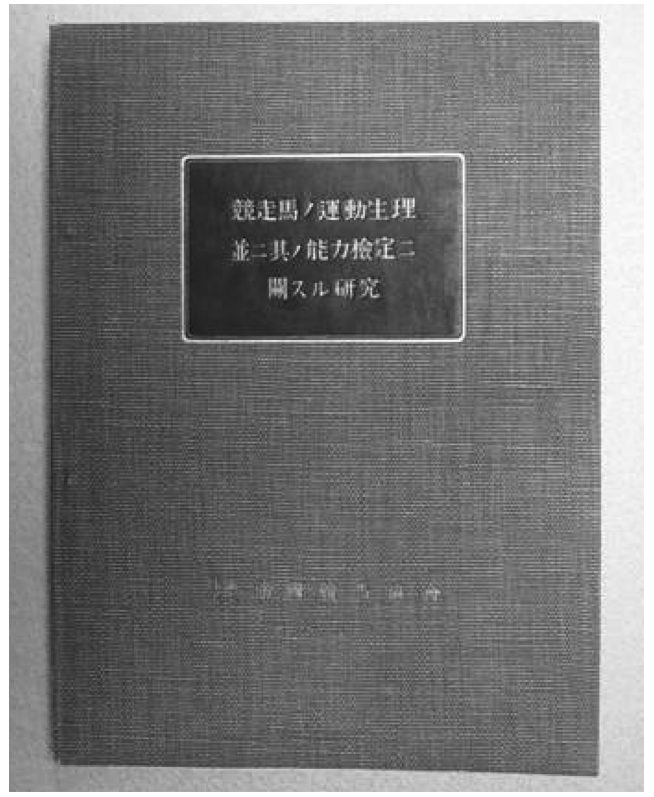

Fig. 1. Studies on exercise physiology and performance testing of the racehorse. This report was a large book of 294 pages (B5 size) consisting of 2 parts; the first part was entitled "Exercise physiology of the racehorse", and the second part was entitled "Performance testing of the racehorse".

Koiwai Farm, the two greatest farms for racehorses at that time, and included a total of 92 Thoroughbred racehorses, were reported in this book. Drs. Matsuba and Shimamura of The University of Tokyo played major roles in this study, and were assisted by 25 students. This project was performed as a commissioned research project from the Teikoku Keiba Kyokai (the Imperial Racing Association). Because this report was written using an archaic form of Japanese language characters, it is very difficult to read in the current era. Nevertheless, it was a valuable contribution because the raw numbers for every variable measured were cited and it contained a large number of data tables (Table $1)$.

The first chapter of the first portion of the book began with a sentence regarding the factors necessary for exercise including healthy internal organs and tough skeletal muscles, especially for racehorses for which high speeds must be attained within a short time. Matsuba and Shimamura stated that the reason why this project was performed was that while there were many papers on the exercise physiology of the warhorse at that time, there were few reports on the exercise physiology of the racehorse. As an overall research plan, the first and second years were considered to be preparatory periods for conducting research on the exercise physiology of the racehorse, and the third to fifth years were to be intensive periods for research on exercise physiology 
Table 1. Raw numbers and percentages for pulse rate obtained at the Koiwai Farm during the period of July 29th to August 7th, 1931

\begin{tabular}{|c|c|c|c|c|c|c|c|c|c|c|}
\hline \multirow{2}{*}{ Horse name } & \multicolumn{5}{|c|}{ Raw number } & \multicolumn{5}{|c|}{ Percentage } \\
\hline & Pre & Post & $1 \mathrm{hr}$ & $2 \mathrm{hr}$ & $3 \mathrm{hr}$ & Pre & Post & $1 \mathrm{hr}$ & $2 \mathrm{hr}$ & $3 \mathrm{hr}$ \\
\hline Dai 4 Rachidia & 34 & 106 & 40 & 34 & 34 & 100.0 & 310.3 & 117.7 & 100.0 & 100.0 \\
\hline Shining star & 33 & 98 & 41 & 35 & 36 & 100.0 & 297.0 & 123.4 & 106.1 & 109.1 \\
\hline Dai 6 Shian Mor & 34 & 112 & 39 & 36 & 37 & 100.0 & 329.4 & 109.5 & 105.9 & 108.8 \\
\hline Dai 4 Shian Mor & 36 & 116 & 42 & 38 & 36 & 100.0 & 322.2 & 113.8 & 105.5 & 100.0 \\
\hline Dai 2 Shian Mor & 34 & 94 & 40 & 39 & 37 & 100.0 & 276.4 & 117.7 & 114.7 & 108.8 \\
\hline Dai 3 Shian Mor & 30 & 102 & 37 & 34 & 34 & 100.0 & 340.0 & 123.3 & 113.3 & 113.3 \\
\hline Dai 5 Shian Mor & 34 & 104 & 44 & 36 & 34 & 100.0 & 305.8 & 129.4 & 105.9 & 100.0 \\
\hline Dai 7 Shian Mor & 36 & 98 & 36 & 32 & 32 & 100.0 & 272.2 & 100.0 & 88.1 & 88.1 \\
\hline Dai 19 Koiwai & 30 & 94 & 37 & 33 & 30 & 100.0 & 313.3 & 123.2 & 110.0 & 100.0 \\
\hline Average & 33.4 & 102.7 & 39.6 & 35.2 & 34.4 & 100.0 & 307.5 & 118.6 & 105.4 & 103.0 \\
\hline
\end{tabular}

Trot $800 \mathrm{~m}$, Canter 1,600 m, Gallop $800 \mathrm{~m}$. The person in charge of experiment: Shigeo Matsuba. Cited from a report by Matsuba and Shimamura [19].

Table 2. Summary of surveys

\begin{tabular}{|c|c|c|c|c|}
\hline Number & Date & Place & Horse & Exercise protocol \\
\hline $1 \mathrm{st}$ & 1928 (Aug. 14th-21st) & Shimofusa farm & 6 (6 four-yo: 6 colts) & $\mathrm{C}(11,200 \mathrm{~m})$ \\
\hline 2nd & 1928 (Nov. 12th-20th) & Shimofusa farm & 7 ( 3 two-yo \& 4 four-yo: 4 colts \& 3 fillies) & $\mathrm{C}(6,400 \mathrm{~m})$ \\
\hline $3 \mathrm{rd}$ & 1929 (Jul. 16th-26th) & Shimofusa farm & $\begin{array}{l}10 \text { ( } 7 \text { two-yo \& } 3 \text { three-yo: } 3 \text { colts, } 2 \text { fillies } \\
\quad \& 5 \text { geldings) }\end{array}$ & $\mathrm{C}(5,000 \mathrm{~m}), \mathrm{W}(200 \mathrm{~m})$, or T $(200 \mathrm{~m})$ \\
\hline 4 th & 1929 (Jul. 16th-24th) & Shimofusa farm & $\begin{array}{l}10 \text { ( } 2 \text { two-yo, } 6 \text { three-yo \& } 2 \text { four-yo; } \\
10 \text { geldings })\end{array}$ & $\mathrm{C}(5,000 \mathrm{~m}), \mathrm{W}(200 \mathrm{~m})$, or T $(200 \mathrm{~m})$ \\
\hline 5 th & 1930 (Mar. 22nd-31st) & Shimofusa farm & 9 (9 two-yo: 9 colts $)$ & $\mathrm{T}(800 \mathrm{~m})+\mathrm{C}(1,600 \mathrm{~m})+\mathrm{G}(800 \mathrm{~m})$ \\
\hline 6 th & 1931 (Mar. 16th-31st) & Shimofusa farm & 15 (15 two-yo: 7 colts \& 8 fillies) & $\mathrm{T}(800 \mathrm{~m})+\mathrm{C}(1,600 \mathrm{~m})+\mathrm{G}(800 \mathrm{~m})$ \\
\hline 7 th & 1931 (Jul. 29th-Aug. 7th) & Koiwai farm & 9 (9 two-yo: 9 colts) & $\mathrm{T}(800 \mathrm{~m})+\mathrm{C}(1,600 \mathrm{~m})+\mathrm{G}(800 \mathrm{~m})$ \\
\hline 8 th & 1932 (Jun. 18th-24th) & Shimofusa farm & 16 (16 two-yo: 8 colts $\& 8$ fillies $)$ & $\mathrm{T}(800 \mathrm{~m})+\mathrm{C}(1,600 \mathrm{~m})+\mathrm{G}(800 \mathrm{~m})$ \\
\hline 9th & 1932 (Aug. 3rd-6th) & Koiwai farm & 10 (10 two-yo: 3 colts \& 7 fillies $)$ & $\mathrm{T}(800 \mathrm{~m})+\mathrm{C}(1,600 \mathrm{~m})+\mathrm{G}(800 \mathrm{~m})$ \\
\hline
\end{tabular}

Although various exercise protocols were used in the 1st and 2nd years (1st to 4th surveys), the same exercise protocol was used from the $3 \mathrm{rd}$ to 5th years (5th to 9th surveys). W, walk; T, trot; C, canter; and G, gallop. two-yo, 2-year-old-horse; three-yo, 3-year-old-horse; and four-yo, 4-year-old-horse. Cited from a report by Matsuba and Shimamura [19].

and for evaluating performance testing of racehorses.

They stated that they decided to measure many variables because most previous studies on the exercise physiology of racehorses had measured only a couple of variables. Accordingly, 20 variables were recorded in this study. The first seven variables studied were defined as being clinical variables, and the eighth to twentieth variables were defined as blood variables as follows: 1) body temperature, 2) respiratory frequency, 3) pulse rate, 4) blood pressure, 5) cardiac function (auscultation of cardiac sound), 6) state of conjunctiva, 7) state of perspiration, 8) specific gravity of blood, 9) erythrocyte count, 10) leukocyte count, 11) hemoglobin concentration, 12) packed cell volume (PCV), 13) viscosity of blood, 14) blood glucose concentration, 15) plasma $\mathrm{CO}_{2}$ concentration, 16) plasma $\mathrm{pH}$, 17) serum freezing point depression, 18) serum refractive index, 19) erythrocyte fragility, and 20) serum spectrogram. Fourteen of these variables were measured during the first year, and all 20 variables were measured in the fourth year, while 10 variables were measured in the fifth year. Measurements were made before exercise (Pre), just after exercise (Post), $1 \mathrm{hr}$ after exercise ( $1 \mathrm{hr}), 2 \mathrm{hr}$ after exercise ( $2 \mathrm{hr}$ ), and $3 \mathrm{hr}$ after exercise ( $3 \mathrm{hr}$ ).

A summary of surveys and actual performance protocols is provided in Table 2. The total number of Thoroughbred racehorses used in this study was 92 (71 two-year-old, 9 three-year-old, and 12 four-year-old; 49 colts, 28 fillies, and 15 geldings), and all were raised at either the Shimofusa Imperial Farm or the Koiwai Farm. Surveys were performed a total of nine times between 1928 and 1932. The total duration of each survey was long, and a total of 61 days were used for the surveys. Although a variety of exercise protocols were used during the first and second years (the first to fourth surveys), the same exercise protocol (Trot, $800 \mathrm{~m}$, Canter, 1,600 m, Gallop, $800 \mathrm{~m}$ ) was used from the third to fifth years (the fifth to ninth surveys). In this article, the authors showed changes in selected variables. Although data were plotted individually in the original report (Fig. 2), 
the authors generated graphs (mean $\pm \mathrm{SD}$ ) using data from tables obtained during the seventh survey on July 29, 1931, at the Koiwai farm.

It was showed that average body temperature rose from $38.1^{\circ} \mathrm{C}$ to $39.5^{\circ} \mathrm{C}$ from Pre to Post and returned to Pre values within $2 \mathrm{hr}$ after exercise. They mentioned that the temperature increase was larger for a canter than for a walk and trot and was larger during a canter of longer distance than for a shorter canter.

Respiratory frequency (RF) was measured based on counting movements of the ribcage or the upper flank with the naked eye. Average RF increased from 12.4 breath/ $\mathrm{min}$ at Pre to $71.3 \mathrm{breath} / \mathrm{min}$ at Post and decreased to 21.4 breath $/ \mathrm{min}$ at $1 \mathrm{hr}$ and $14.7 \mathrm{breath} / \mathrm{min}$ at $3 \mathrm{hr}$ (Fig. 3). They noted that because RF was very changeable just after exercise, rapid measurements would be required to accurately measure it. In 1944, Okabe and Sugiyama [35] measured RF continuously during exercise at a walk, trot, and canter by recording expiratory sound with a microphone attached near a nostril and reported that RF immediately after exercise differed completely from RF during exercise because a very rapid decrease in RF occurred just after finishing exercise.

Pulse rate was measured by auscultation. The mean pulse rate at Pre was 33.4 beat/min and increased to 102.7 beat/min at Post, after which it decreased to 39.6 beat/ min at $1 \mathrm{hr}$ after exercise and $34.4 \mathrm{beat} / \mathrm{min}$ at $3 \mathrm{hr}$ after exercise (Fig. 4). Although it was considered that heart rate (HR) measurement was preferable to that of pulse rate by auscultation, recording of electrocardiograms (ECGs) of horses to calculate HR was impossible at that time, even at rest. Moreover, although pulse rate immediately after exercise was also measured by auscultation, because direct measurement of HR during exercise was impossible at the time, pulse rate immediately after exercise was considered to indicate HR during exercise. Considering this situation, it seemed that the measurement of pulse rate was unavoidable. The first ECG recordings of horses in Japan were carried out in 1944 by Yasuda et al. [53], and the first ECG recording in the world of a horse during field exercise that included fast galloping was carried out in 1964 by Nomura et al. [27, 28].

Blood pressure was measured in these studies using the Tycos sphygmomanometer at the point of the radial artery, and systolic pressure was recorded by measuring pulses of the digital artery. Average blood pressure increased from $156 \mathrm{mmHg}$ at Pre to $238 \mathrm{mmHg}$ at Post and then decreased to $176 \mathrm{mmHg}$ at $1 \mathrm{hr}$ and $158 \mathrm{mmHg}$ at $3 \mathrm{hr}$ after exercise (Fig. 5). It was noted that blood pressure increased even at lower intensity exercise, but the magnitude of the increase was much larger with higher intensity exercise. Although the average value of $156 \mathrm{mmHg}$ at Pre was considered to be relatively high, it is unknown if the values had been converted to account for hydrostatic pressure differences to

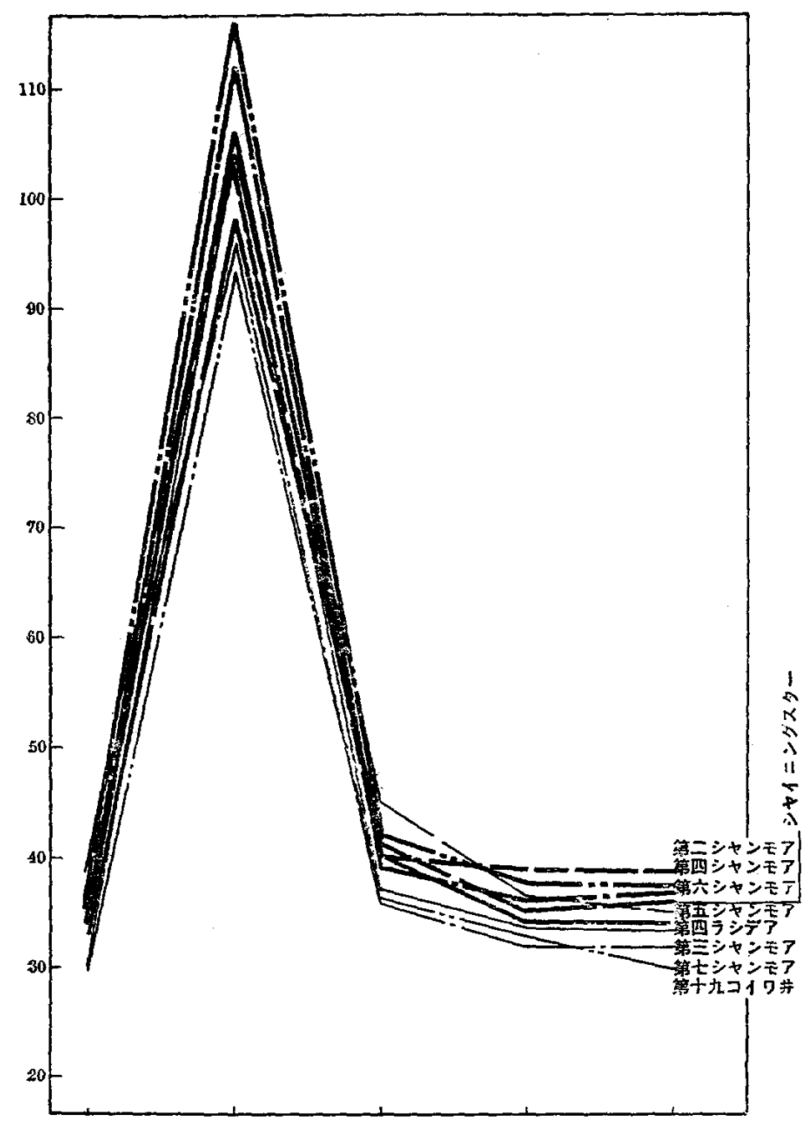

Fig. 2. Pulse rate measured at the Koiwai Farm in 1931 (July 29th-August 7th). Data obtained from each horse were plotted individually. Cited from a report by Matsuba and Shimamura [19].

the values at the height of the heart or not. Considering the difference in height between the height of the radial artery and the heart, the reported values might be reasonable, even if the values were not converted.

The average erythrocyte count at rest of Thoroughbred racehorses was noted to be markedly higher than those of half-blooded horses. Erythrocyte counts increased by about $20-30 \%$ with exercise, and it returned to the Pre value by $1 \mathrm{hr}$ after exercise (Fig. 6). The average PCV at rest was approximately $40 \%$ and was higher than that of other types of horses. PCV increased to about $50 \%$ at Post and decreased to almost the Pre value $1 \mathrm{hr}$ after exercise. Matsuba and Shimamura speculated that one of the main reasons for these increases after exercise might be water loss caused by exercise. Approximately 40 years later, the reason for these changes was clarified by Persson et al. [37]. They performed splenectomies on Standardbred trotting horses and found that the equine spleen can release erythrocyterich blood into the systemic circulation during exercise, increasing the erythrocyte count and PCV. 


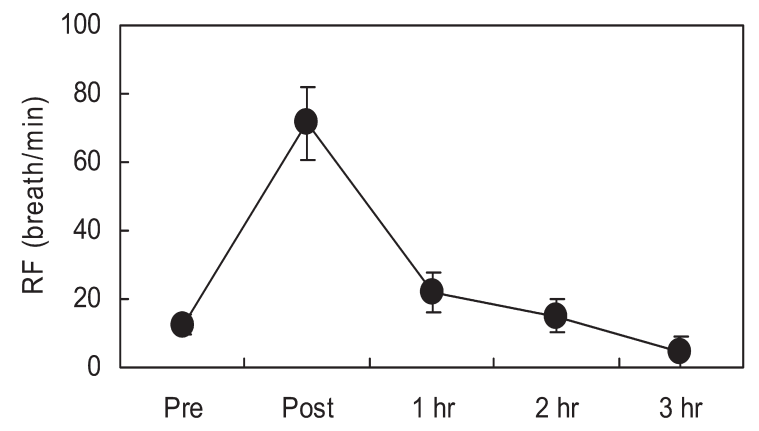

Fig. 3. Changes in respiratory frequency (RF) at different times relative to exercise. The authors generated this graph using data from a table in a report by Matsuba and Shimamura [19].

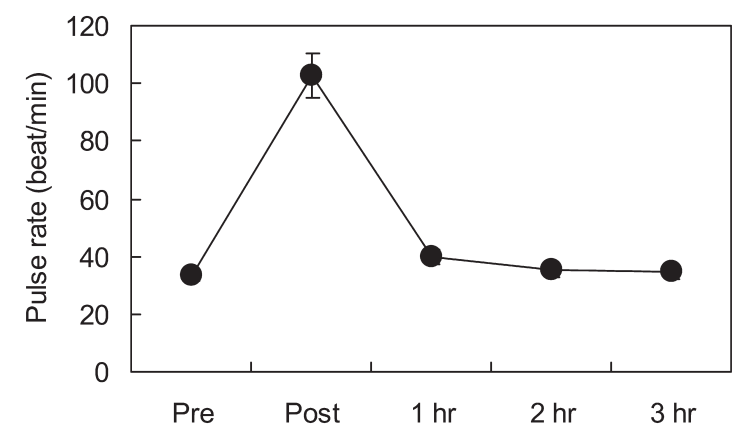

Fig. 4. Changes in pulse rate at different times relative to exercise. The authors generated this graph using data from a table in a report by Matsuba and Shimamura [19].

The average hemoglobin $(\mathrm{Hb})$ concentration at Pre was $14.2 \mathrm{~g} / \mathrm{d} l$, increased to $20.0 \mathrm{~g} / \mathrm{d} l$ at Post, and then decreased gradually to $16.0 \mathrm{~g} / \mathrm{d} l$ at $1 \mathrm{hr}$ and $14.6 \mathrm{~g} / \mathrm{d} l$ at $3 \mathrm{hr}$ (Fig. 7). They stated that the reason for the increase in $\mathrm{Hb}$ concentration was due to the increased erythrocyte count because $\mathrm{Hb}$ exists inside of red blood cells. When blood viscosity was defined as its ratio to the viscosity of water (water viscosity $=1.000$ ), it was 5.0-6.0 at rest. The average blood viscosity was 6.4 at Pre and increased to 10.6 with exercise, and returned to the Pre value at $1 \mathrm{hr}$ after exercise.

\section{Performance Testing Using Recovery Rate as an Index}

The second part of the publication described the recovery rate of racehorses. When Matsuba and Shimamura looked at all data on changes in variables induced by exercise that were measured in a single horse during the first and second years of the study (1928 and 1929), they noticed there was a tendency for many variables measured in horses considered to be fitter to recover to their Pre values more rapidly than

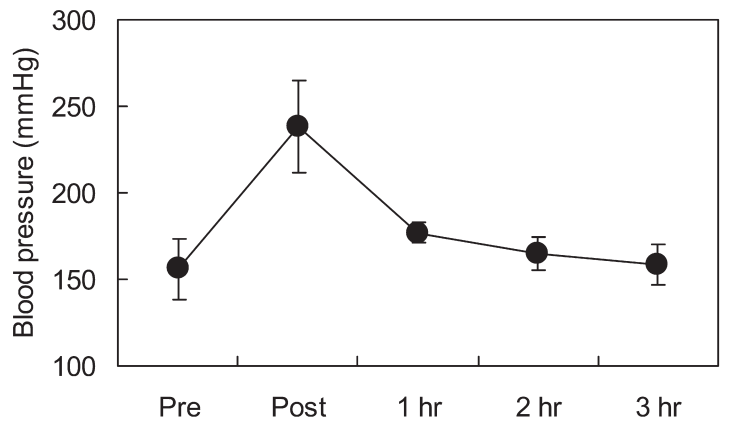

Fig. 5. Changes in blood pressure at different times relative to exercise. The authors generated this graph using data from a table in a report by Matsuba and Shimamura [19].

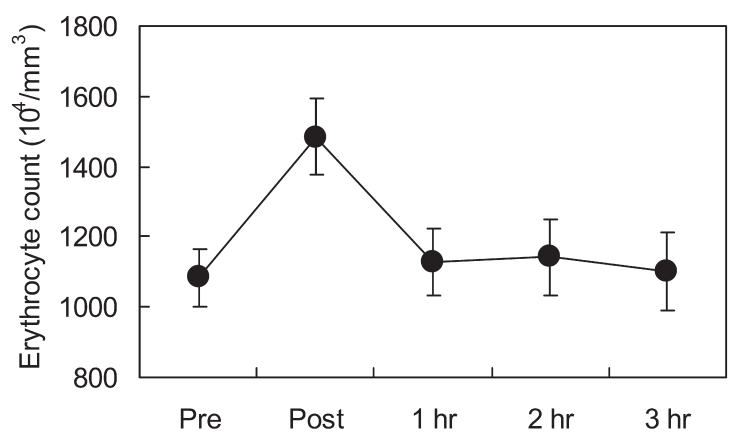

Fig. 6. Changes in erythrocyte count at different times relative to exercise. The authors generated this graph using data from a table in a report by Matsuba and Shimamura [19].

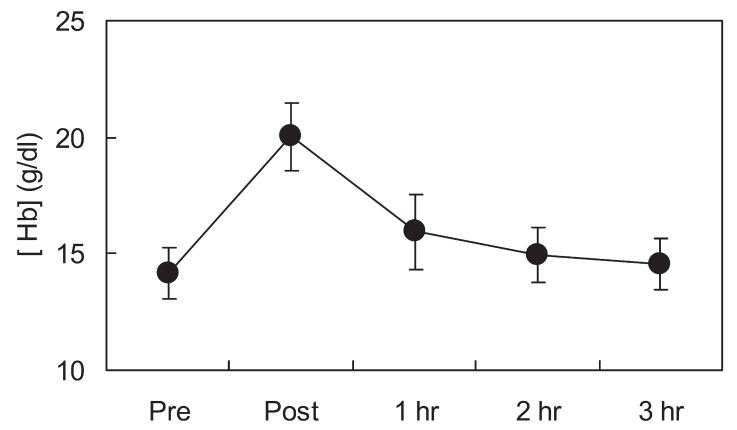

Fig. 7. Changes in hemoglobin concentration ([Hb]) at different times relative to exercise. The authors generated this graph using data from a table in a report by Matsuba and Shimamura [19].

those of other horses; that is, it appeared that an excellent horse could recover from fatigue caused by intense exercise more rapidly than other horses. Accordingly, they decided to evaluate the recovery status of each variable by calculating the percentage of its Pre value at different times during 
Table 3. Raw numbers and percentages for Yamaougi in the 5th survey at the Shimofusa Imperial Farm in March 1930

\begin{tabular}{|c|c|c|c|c|c|c|c|c|c|c|}
\hline \multirow{2}{*}{ Examines item } & \multicolumn{5}{|c|}{ Raw number } & \multicolumn{5}{|c|}{ Percentage } \\
\hline & Pre & Post & $1 \mathrm{hr}$ & $2 \mathrm{hr}$ & $3 \mathrm{hr}$ & Pre & Post & $1 \mathrm{hr}$ & $2 \mathrm{hr}$ & $3 \mathrm{hr}$ \\
\hline Body temperature & 38 & 38.7 & 38.4 & 38.4 & 38.6 & 100.0 & 108.8 & 105.0 & 105.0 & 107.5 \\
\hline Respiratory rate & 15 & 38 & 26 & 20 & 18 & 100.0 & 253.3 & 173.3 & 133.3 & 130.0 \\
\hline Pulse rate & 36 & 72 & 41 & 36 & 36 & 100.0 & 200.0 & 113.9 & 100.0 & 100.0 \\
\hline Blood pressure & 164 & 194 & 174 & 178 & 174 & 100.0 & 118.4 & 106.1 & 108.5 & 106.1 \\
\hline Specific gravity of blood & 1.054 & 1.054 & 1.054 & 1.030 & 1.054 & 100.0 & 100.0 & 100.0 & 98.1 & 100.0 \\
\hline Blood viscosity & 4.8 & 4.5 & 4.9 & 4.9 & 4.8 & 100.0 & 93.8 & 102.1 & 102.1 & 100.0 \\
\hline [Hemoglobin] & 9.5 & 10.5 & 10.6 & 10.0 & 9.7 & 100.0 & 109.7 & 111.3 & 104.8 & 101.6 \\
\hline Erythrocyte count & 7,760 & 9,440 & 9,176 & 8,744 & 8,640 & 100.0 & 121.6 & 118.2 & 112.7 & 111.3 \\
\hline Leukocyte count & 10,100 & 10,900 & 11,550 & 10,555 & 11,220 & 100.0 & 107.9 & 114.4 & 104.5 & 111.1 \\
\hline Blood glucose & 107 & 90 & 90 & 95 & 95 & 100.0 & 84.1 & 84.1 & 89.0 & 89.0 \\
\hline $\mathrm{CO}_{2}$ concentration & 59.4 & 55.5 & 55.5 & 56.5 & 59.4 & 100.0 & 93.4 & 93.4 & 95.1 & 100.0 \\
\hline
\end{tabular}

Percentages in boldfaced type indicate that the parameter recovered to $100 \pm 5 \%$. Cited from a report by Matsuba and Shimamura [19].

recovery. In the case of body temperature, when recovery state was evaluated, the numbers used for calculation were the raw temperature data minus 30 , because the rate of increase in body temperature sometimes did not exceed $5 \%$. For the same reason, data used for specific gravity of blood measurements were the raw data minus 1.000.

As mentioned above, measurements of 20 variables were carried out a total of five times before exercise (Pre), just after exercise (Post), $1 \mathrm{hr}$ after exercise (1 hr), $2 \mathrm{hr}$ after exercise (2 hr), and $3 \mathrm{hr}$ after exercise ( $3 \mathrm{hr}$ ). Later, the number of variables was decreased to 11 , as shown in Table 3. The percentage of the Pre value for each variable at $1 \mathrm{hr}, 2 \mathrm{hr}$, and $3 \mathrm{hr}$ was calculated. When the percentage reached within $100 \pm 5 \%$ (95-105\%) compared with the Pre value, the variable was considered to be recovered. Then the percentage of the total number of recovered variables at each time (RR at 1 hr [RR@1hr], RR at 2 hr [RR@2hr], and RR at $3 \mathrm{hr}$ [RR@3hr]; where RR is recovery rate) was calculated, and an overall average was calculated from these ((RR@1hr+RR@2hr + RR@3hr)/3)); the authors proposed calling this overall average the "recovery rate" of each horse.

They found a tendency for horses in good condition to have a lower increase in pulse rate after constant exercise, and the blood pressure of these horses tended to be higher. Based on these observations, they thought that the $\mathrm{d} / \mathrm{p}$ ratio (where $\mathrm{d}$ is the blood pressure difference between Pre and Post and $\mathrm{p}$ is the pulse rate difference between Pre and Post) might become larger as training advanced. They named the $\mathrm{d} / \mathrm{p}$ ratio the "pulse pressure ratio" and considered that it might be a valuable index for evaluating fitness of racehorses in future research. Additionally, measurement of pulse rate and blood pressure was thought to be useful because they could be obtained noninvasively.

The recovery rate and $d / p$ ratio were obtained from every
Table 4. Calculation of the recovery rate for Yamaougi

\begin{tabular}{lrrr}
\hline & $1 \mathrm{hr}$ & $2 \mathrm{hr}$ & $3 \mathrm{hr}$ \\
\hline Number of examined items & 11 & 11 & 11 \\
Number of recovered items & 3 & 7 & 5 \\
Recovery rate & 0.27 & 0.64 & 0.45 \\
\hline
\end{tabular}

The recovery rate was $0.27(3 / 11)$ at $1 \mathrm{hr}, 0.64(7 / 11)$ at $2 \mathrm{hr}$, and 0.45 $(5 / 11)$ at $3 \mathrm{hr}$. The authors generated this table using data from a table in a report by Matsuba and Shimamura [19].

horse for all surveys from the fifth through the ninth. Table 3 shows results from a single horse, Yamaougi, collected during the fifth survey in March 1930. Percentages in boldfaced type show that this variable had recovered to within $100 \pm 5 \%$. As shown in Table 4 , the recovery rate was 0.27 $(3 / 11$ variables $)$ at $1 \mathrm{hr}, 0.64(7 / 11)$ at $2 \mathrm{hr}$ and $0.45(5 / 11)$ at $3 \mathrm{hr}$, and the overall average was $0.45((0.27+0.64+$ $0.45) / 3$ ). Table 5 shows a summary of results of the fifth survey.

A follow-up survey was conducted on the relationship between recovery rate and racing performance of 25 horses whose records could be traced over their entire racing careers. A horse's winning percentage was selected as its index of performance, and the relationship between winning percentage and recovery rate was found to be positively correlated (Fig. 8). However, Matusba and Shimamura pointed out that although the recovery rate could indicate the fitness level and capacity for performance at the time when the recovery rate was measured, because this index was obtained from a single measurement at the time a horse was 2 years old, recovery rate would not be particularly useful for evaluating performance after a horse had undergone training and started racing. It was recommended that it would be necessary to make multiple recordings of the recovery rate in order to evaluate a horse's racing perfor- 
Table 5. Summary of results of the 5th survey conducted during March 1930 at the Shimofusa Imperial Farm

\begin{tabular}{clccccc}
\hline \multirow{2}{*}{ Number } & \multirow{2}{*}{ Name } & \multirow{2}{*}{ Recovery rate } & \multicolumn{3}{c}{ Recovery rate at each time } & \multirow{2}{*}{$\mathrm{d} / \mathrm{p}$} \\
\cline { 4 - 5 } & & 0.82 & $1 \mathrm{hr}$ & $2 \mathrm{hr}$ & $3 \mathrm{hr}$ & \\
\hline 1 & Yamayoshi & 0.70 & 0.73 & 0.91 & 0.91 & 2.21 \\
2 & Yamanari & 0.64 & 0.55 & 0.73 & 0.64 & 2.16 \\
3 & Yamahisa & 0.60 & 0.45 & 0.64 & 0.73 & 1.81 \\
4 & Yamahide & 0.58 & 0.55 & 0.64 & 0.55 & 1.73 \\
5 & Yamataka & 0.58 & 0.45 & 0.55 & 0.73 & 1.52 \\
6 & Yamamichi & 0.51 & 0.45 & 0.64 & 0.45 & 1.30 \\
7 & Yamamune & 0.48 & 0.50 & 0.45 & 0.45 & 1.50 \\
8 & Yamanobu & 0.43 & 0.20 & 0.60 & 0.50 & 1.83 \\
9 & Yamaougi & &
\end{tabular}

$\mathrm{d} / \mathrm{p}$ : ratio of $\mathrm{d}$ (blood pressure difference between Pre and Post) and $\mathrm{p}$ (pulse rate difference between Pre and Post). Cited from a report by Matsuba and Shimamura [19].

mance exactly. Finally, they mentioned that since there are numerous factors that can influence racing performance, it would be difficult to predict performance by using only the single variable of recovery rate. They proposed that both talent and training are important factors that have an influence on a horse's performance and emphasized the importance of training and of the need for research on the effects of training.

Kimata, who was a student of Matsuba, wrote interpretive articles in a journal for veterinarians on the exercise physiology of animals, which at that time was a new concept in veterinary medicine [10-18]. In those articles, he described in detail the effects of exercise on body temperature, respiration, pulse rate, and blood temperature. He also provided detailed explanations of recovery rate, training, and fatigue.

\section{Effect of Training on Performance of the Racehorse}

Matsuba and Shimamura established new methods for performance testing of racehorses and indicated that studies on the effects of training would become an important area of research in the future. Accordingly, a series of experiments on the effects of training were conducted at the Nakayama Race Club (now Nakayama Racecourse of the Japan Racing Association) over a total of four years. A research report entitled "Studies on the performance and training of the racehorse", which contained results of those experiments, was published in 1939 by Matsuba [25]. This report was a large book of 492 pages (A5 size) and mainly dealt with the effects of training; the report covered physical changes of blood characteristics with training. All of the results were published as five papers in The Journal of the Central Society for Veterinary Medicine in 1938 [20-24]. The series of experiments was carried out over a total of four years

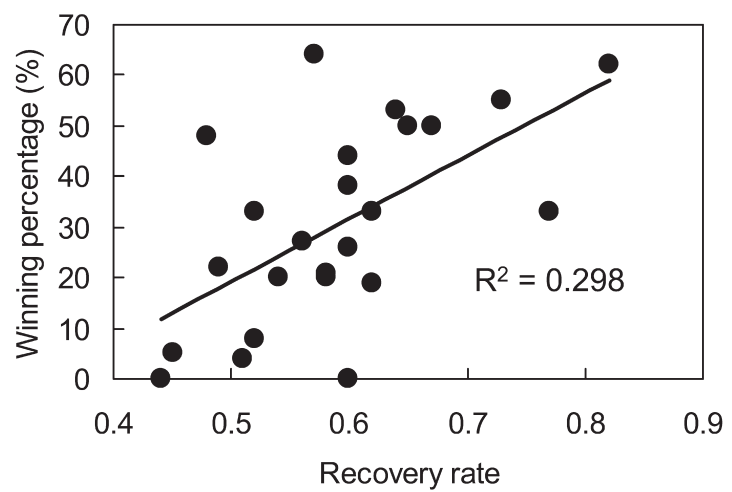

Fig. 8. Relationship between winning percentage and recovery rate. The authors generated this graph using data from a table in a report by Matsuba and Shimamura [19].

during the periods of 1933-1934 and 1936-1937. This project was carried out as research commissioned by the Teikoku Keiba Kyokai (the Imperial Racing Association).

Although it had become possible to evaluate the performance of racehorses by using the new index, the recovery rate [19], the study that introduced the recovery rate had been performed on 2-year-old racehorses trained on training farms, and the horses had not yet raced. Therefore, Matsuba decided to perform a series of experiments on racehorses trained at racecourses in order to better understand their exercise physiology and performance. However, he had been thinking that because it was not easy to evaluate performance even on training farms where it was possible to conduct standardized and regulated exercise tests under controlled experimental conditions, it would be difficult to perform standardized exercise tests under nonexperimental situations, e.g., during actual training at a racecourse.

Accordingly, as the first experiment, he decided to 
evaluate the training method that racehorses actually used at the Nakayama Race Club in order to understand its effects on exercise physiological variables and create a database for future studies Matsuba dubbed the training method that was being used at Nakayama Race Club "the present method of training".

Four 2-year-old racehorses were used in this study. Training was carried out from the end of July to the beginning of December in 1933. Table 6 shows feeding regimens in September. During the training period, horses were trained with practical methods and ran several times at speeds assumed to be maximal during racing. The training period was divided into 3 stages. The first stage began on July 25th, and a maximal speed run was carried out on October 14th. In the second stage, which began on October 15 th, after a short period of rest, training was carried out, and a maximal speed run was then conducted on November 21 st. In the third stage, which began on November 22nd, after a short period of rest, training was again started, and a maximal speed run was carried out on December 9th. Table 7 shows the training record of one horse. The distance of an intensive gallop workout was 1,600 $\mathrm{m}$ in most cases, and the time required to complete it was $110 \mathrm{sec}$; the horse's average speed was $14.5 \mathrm{~m} / \mathrm{sec}(13.8 \mathrm{sec} / 200 \mathrm{~m})$. This workout was relatively longer in distance than those currently used. The canter distance on a typical day was also $1,600 \mathrm{~m}$, and its average speed was $11.1-11.7 \mathrm{~m} / \mathrm{sec}(17-18 \mathrm{sec} / 200 \mathrm{~m})$, while the distance trotted was 1,600-3,200 m. In general, the distance trotted was longer and the distance cantered on a typical day was shorter compared with protocols used currently.

Five clinical variables (body temperature, respiratory frequency, pulse rate, blood pressure, and cardiac sounds) were measured once each week. Three variables (erythrocyte count, blood glucose concentration, and blood $\mathrm{CO}_{2}$ concentration) were measured about once every two weeks as an examination of blood characteristics. Urine analysis included eleven variables (color, turbidity, $\mathrm{pH}$, specific gravity, viscosity, glucose concentration, protein concentration, phosphoric acid concentration, total nitrogen concentration, creatinine concentration, and indican) that were measured every 10 days. Six variables (height, body weight, chest circumference, cannon circumference, chest cross-sectional area, and cannon cross-sectional area) were measured every two weeks during a physical examination. Seven variables (body temperature, respiratory frequency, pulse rate, blood pressure, erythrocyte count, blood glucose concentration, and blood $\mathrm{CO}_{2}$ concentration) were measured four times at the time of mock races on September 30th, November 21 st, November 28th, and December 9th.

The results of monitoring clinical variables that were ovserved with the progress of training were as follows: 1)
Table 6. Feeding regimens in September at the Nakayama Race Club

\begin{tabular}{lcrrr}
\hline \multicolumn{1}{c}{ September } & Morning & Noon & Evening & Night \\
\hline Oats $(\mathrm{g})$ & 630 & 840 & 840 & \\
Wheat bran $(\mathrm{g})$ & 220 & 220 & 220 & \\
Chaff $(\mathrm{g})$ & 2,260 & 2,260 & 2,260 & \\
Grass $(\mathrm{g})$ & & & & 3,000 \\
Salt $(\mathrm{g})$ & 22.6 & 22.6 & 22.6 & \\
Fresh forage (g) & & 15,000 (per day) & \\
\hline
\end{tabular}

Cited from a report by Matsuba [25].

body temperature was unchanged, 2) respiratory frequency decreased, 3) pulse rate decreased, 4) blood pressure increased, and 5) cardiac sounds became clearer. Matsuba suggested that changes observed in pulse rate, blood pressure, and cardiac sounds were related to improved cardiac function and that the decrease in pulse rate was associated with an increased stroke volume. In addition, because pulse rate was increased by a short period of rest from November $22 \mathrm{nd}$, it was suggested that there would be interesting relationships between training and pulse rate.

Changes in blood variables with the progression of training were as follows: the erythrocyte count and blood glucose increased, and the blood $\mathrm{CO}_{2}$ concentration initially increased but later decreased. Changes in urine variables occurred irregularly and appeared not to be useful as an index. Most variables associated with the physical examination, including body weight, did not change during the training period. Changes in the recovery rate throughout the training period were small, and in some cases, the recovery rate tended to decrease when training intensified due to conduct of maximal speed runs. Moreover, considerable variability occurred in both the recovery rate and pulse pressure ratio. Matsuba suggested that the cause of these results was that the same exercise protocol was not used. Based on these results, he concluded that the present method of training was not the optimal training method to improve racehorse performance and that there was room for improvement.

The second experiment was performed by using a new training method that was a modified version of the present method of training. Matsuba named the training method used for this study the "conservative method of training". Four 2-year-old racehorses were studied, and training was conducted from April to October in 1934. The training intensity was lower and the trotting distance was shorter compared with the present method of training, and the training intensity was gradually increased. Clinical, blood, urine, feces, and physical examinations were all performed once per week, and a performance test was conducted once every two weeks. The clinical, blood, and urine variables 
Table 7. Training protocol for a horse during the period of September to October

\begin{tabular}{rccccc}
\hline & Trot $(\mathrm{m})$ & $\begin{array}{c}\text { Canter } \\
(\mathrm{m})\end{array}$ & $\begin{array}{c}\text { Total time } \\
(\mathrm{sec})\end{array}$ & $\begin{array}{c}\text { Gallop } \\
(\mathrm{m})\end{array}$ & $\begin{array}{c}\text { Total time } \\
(\mathrm{sec})\end{array}$ \\
\hline Sep. 25 & 3,200 & 1,600 & 136 & & \\
26 & 3,200 & 1,600 & 136 & & \\
27 & 1,600 & & & 1,600 & 119 \\
28 & 2,400 & 1,600 & 136 & & \\
29 & 1,600 & 1,600 & 136 & & \\
30 & 1,600 & 1,600 & 131 & 800 & 52.3 \\
Oct. 1 & 3,200 & & & & \\
2 & 2,400 & 800 & 136 & & \\
3 & 1,600 & 1,600 & 136 & & \\
4 & 1,600 & & & 1,600 & 112 \\
5 & 3,200 & 1,600 & 136 & & \\
6 & 1,600 & 1,600 & 126 & & \\
7 & 1,600 & & & 1,600 & 108 \\
8 & 3,200 & & & & \\
9 & 2,400 & 800 & 126 & & \\
10 & 1,600 & 1,600 & 126 & & \\
11 & 1,600 & & & 1,600 & 112 \\
12 & 3,200 & 1,600 & 136 & & \\
13 & 1,600 & 1,600 & 136 & & \\
14 & 1,600 & & & 1,600 & 108 \\
\hline
\end{tabular}

The authors generated this table using data from a table in a report by Matsuba [25].

examined were identical to those in the previous experiment.

The summary of the results of this study was approximately the same as that for the previous study [21]. Because respiratory frequency and pulse rate decreased and blood pressure increased, Matsuba suggested that improvement in cardiovascular function occurred due to the training. On the other hand, because the erythrocyte count and blood glucose concentration increased only slightly, but the blood $\mathrm{CO}_{2}$ concentration did not change, he concluded that blood characteristics may have properties that are not affected by excessive training.

In this study, although the running distance and dates of the performance tests were designed to be held constant, it proved to be difficult to set a constant running speed due to weather, track condition, and the occurrence of various diseases. Therefore, although variations in the results were observed, he concluded that relatively constant data were obtained compared with the previous experiment. However, since changes in the recovery rate and pulse pressure ratio were small, he considered that there was no improvement in performance. Matsuba concluded that the training method used in this study was safe because all horses finished the study able to participate in a race; however, he considered this method was slightly inferior to the present method of training that was being used and that future studies would be needed to evaluate positive effects of training on racehorse performance.

Matsuba tried to use a similar protocol for the performance test to calculate the recovery rate, because the recovery status of each variable was largely influenced by the exercise intensity of the performance test. If the performance test was performed on only a single occasion on several horses to evaluate their fitness at that time, it would be easy to set a constant exercise intensity for all the horses by making all the horses run simultaneously in the same group. However, when the effects of training on recovery rate were to be evaluated, the exercise intensities of the performance tests performed multiple times during the training period would need to be set as identical. This was a much more difficult thing to achieve than thought. Moreover, in the field training study, it was difficult to complete the entire training plan without any of the horses experiencing musculoskeletal disorders. In addition, the number of horses Matsuba used in these studies was small. Taking these factors into consideration, the authors thought it unavoidable that the expected results were not obtained in these experiments.

Matsuba also evaluated the effects of administration of various kinds of medicaments on the performance of racehorses using four 2-year-old racehorses. The training was carried out from August to November in 1936. The training protocol used in this study was a modified version of the conservative method with the trotting distance increased. Administration of nine medicaments ( $5 \%$ glucose, $3 \%$ calcium iodide, $20 \%$ benzoic acid Locke's solution, radium Ringer's solution, oxygen inhalation, cam-phenal, vitacamphor, deigalen, and adrenalin Locke's solution) was performed, after which the effects of the drugs on running speed and degree of recovery from fatigue were evaluated. Administration tests were carried out once per week from the middle of September to the end of October (the first and final tests were control tests). For each treatment, the $5 \%$ recovery rate $(100 \pm 5 \%), 10 \%$ recovery rate $(100 \pm 10 \%)$, and pulse pressure ratio were reported.

When evaluation was performed by using the 10\% recovery rate, the best result was obtained with administration of $3 \%$ calcium iodide. However, because the second-best result was obtained in the control tests, Matsuba concluded that the recovery rate tended to decrease simply due to the administration of a medicament. In terms of training regimens, because relatively good results were obtained by increasing the trotting distance, Matsuba suggested that increasing the trotting distance was more essential than increasing the canter distance.

In the final experiment, changes in the blood's physical characteristics were investigated, and the utility of that information for use in regulating training and evaluating 
performance was examined. Four racehorses (2 two-year -old, 1 five-year-old, and 1 six-year-old) were studied. The training was carried out from July to December in 1937. Training regimens used in this study were similar to the protocols used in previous experiments. Five clinical variables, twelve blood variables (erythrocyte count, maximal erythrocyte fragility, minimal erythrocyte fragility, specific gravity, viscosity, erythrocyte sedimentation rate (ESR), $\mathrm{PCV}$, freezing point depression, surface tension, $\mathrm{pH}$, electrical conductivity, and blood $\mathrm{CO}_{2}$ concentration), and seventeen urine variables were measured once per week, and a fecal examination was also performed. Because erythrocyte fragility, blood viscosity, ESR, freezing point depression, and $\mathrm{pH}$ changed with the progression of training, Matsuba suggested that these five variables might be useful indices to study further in the future. Both the maximal and minimal fragility of erythrocytes increased as training advanced; furthermore, blood viscosity increased, and ESR decreased as training progressed. The relationships of ESR with training and condition were later followed up by Sakurai, who had studied under Matsuba [39-43].

\section{Conclusions}

The history of research on the exercise physiology of the horse in Japan began in the 1920s during a time when the warhorse was still the major focus of equine interest, and studies later began to be performed that were focused on racehorses. Drs. Matsuba and Shimamura of The University of Tokyo played major roles in initiating studies of racehorses during the 1930s. Their first study, published in 1933 [19], was the single most important study ever published in the field of equine exercise physiology in Japan. It is remarkable that they were doing research to evaluate performance of racehorses in the 1930s at the dawning of the era of modern horse racing in Japan. It might be said that their study was greatly ahead of its time.

Another interesting point about their study is that data were collected from elite Thoroughbred racehorses such as Wakataka, the winner of the first Japanese Derby held in 1932 at Meguro Racecourse. Wakataka won seven of 11 races in which he ran, including the Emperor's Cup in the autumn of 1932 at Meguro Racecourse. In addition to Wakataka, data were collected from a number of elite racehorses: Happy Chapel, winner of the Emperor's Cup in the spring meeting at Meguro Racecourse in 1932; Hakusetsu, winner of the Emperor's Cup in the autumn meeting at Yokohama Racecourse in 1933; and Ascot, winner of the Emperor's Cup in the spring meeting at Meguro Racecourse in 1933. Later, Ascot participated in Eventing at the Berlin Olympics in 1936 with Baron Nishi, who was the gold medalist in individual show jumping at the Los
Angeles Olympics in 1932. Data have also been collected from several contemporary Japanese Derby winners such as Tanino Gimlet (69th Derby in 2002), Deep Impact (72nd Derby in 2005), Meisho Samson (73rd Derby in 2006), and Logi Universe (76th Derby in 2009), making it all the more remarkable to realize that detailed data from the first winner of the Japanese Derby had been measured.

In recent times, it has become possible to measure cardiopulmonary functions during exercise, such as oxygen uptake, carbon dioxide production, minute ventilation, cardiac output, blood gases, and blood pressures, due to the introduction of equine high-speed treadmills and flow-through gas collection systems. These technological advances have been used for measuring oxygen uptake since 1992 and for evaluating the effects of training on the oxygen transport system, cardiopulmonary function [1-4, 32], and skeletal muscle [26, 49, 50].

At the present time, one of a number of variables that have been measured in field exercise tests, the V200 (running speed at which the HR reaches 200 beat/min) of numerous young horses trained at training farms has been recorded several times during their training periods $[5,33$, $34]$, and the data indicate that this variable may be useful for evaluating fitness and the effects of training. However, it has been impossible to predict future racing performance using only this variable. When the values for the variable VHRmax (running speed at maximal HR) measured in JRA racehorses were compared, it was found that stronger horses (open class in the JRA classification) had higher VHRmax values than other horses (newcomer or maiden class) [6]. However, it was still impossible to determine the performance of a racehorse by using only this variable. Even if maximal oxygen uptake, the best indicator of aerobic work capacity of a racehorse, was measured, it would still not be possible to predict overall performance. The pioneering work of Matsuba and Shimamura created a legacy that continues today as researchers attempt to better understand the factors that determine, and might be used to predict, racehorse performance.

\section{Acknowledgments}

The authors wish to thank Professor James H. Jones of the University of California, Davis, for valuable advice on this paper.

\section{References}

1. Hiraga, A., Kai, M., Kubo, K., and Erickson, B.K. 1995. The effect of long slow distance training on aerobic work capacity in young Thoroughbred horses. J. Equine Sci. 6: 1-6. [CrossRef] 
2. Hiraga, A., Kai, M., Kubo, K., Yamaya, Y., and Erickson, B.K. 1995. The effect of incline on cardiopulmonary function during exercise in the horse. J. Equine Sci. 6: 55-60. [CrossRef]

3. Hiraga, A., Kai, M., Kubo, K., and Sugano, S. 1997. Effects of low intensity exercise during the breaking period on cardiopulmonary function in Thoroughbred yearlings. J. Equine Sci. 8: 21-24. [CrossRef]

4. Hiraga, A., Kai, M., Kubo, K., and Sugano, S. 1997. The effect of training intensity on cardiopulmonary function in 2 year-old Thoroughbred horses. J. Equine Sci. 8: 75-80. [CrossRef]

5. Hiraga, A. 2013. The Racehorse Handbook. pp. 151-152. Maruzen, Tokyo [in Japanese].

6. Hiraga, A. 2013. The Racehorse Handbook. p. 179. Maruzen, Tokyo [in Japanese].

7. Hiroe, I., Nagano, T., and Yasuda, S. 1933. Studies on the influence of work on blood viscosity in the warhorse. $J$. Cent. Soc. Vet. Med. 46: 633-639 [in Japanese]. [CrossRef]

8. Hiroe, I., Nagano, T., and Yasuda, S. 1934. On the relationship between work and the velocity of sedimentation of erythrocytes in the horse. J. Cent. Soc. Vet. Med. 47: 341-349 [in Japanese]. [CrossRef]

9. Ishizaki, S., Honzawa, S., Shinohara, A., and Koyama, K. 1954. Relation between size and working power in the horse. IV. Relation between body weight and work power in the horse. Nihon Chikusan Gakkaiho 25: 168-173 [in Japanese with English figures and summary]. [CrossRef]

10. Kimata, H. 1933. Physiology of muscular exercise in animals. 1. Ouyo Juigaku Zasshi 6: 174-178 [in Japanese].

11. Kimata, H. 1933. Physiology of muscular exercise in animals. 2. Effects of exercise on body temperature. Ouyo Juigaku Zasshi 6: 265-270 [in Japanese].

12. Kimata, H. 1933. Physiology of muscular exercise in animals. 3. Effects of exercise on respiration. Ouyo Juigaku Zasshi 6: 337-341 [in Japanese].

13. Kimata, H. 1933. Physiology of muscular exercise in animals. 4. Effects of exercise on blood response. Ouyo Juigaku Zasshi 6: 411-418 [in Japanese].

14. Kimata, H. 1933. Physiology of muscular exercise in animals. 5. Effects of exercise on pulse rate. Ouyo Juigaku Zasshi 6: 476-482 [in Japanese].

15. Kimata, H. 1933. Physiology of muscular exercise in animals. 6. Effects of exercise on blood pressure. Ouyo Juigaku Zasshi 6: 537-548 [in Japanese].

16. Kimata, H. 1933. Physiology of muscular exercise in animals. 7. About training. Ouyo Juigaku Zasshi 6: 691-697 [in Japanese].

17. Kimata, H. 1933. Physiology of muscular exercise in animals. 8. About fatigue. Ouyo Juigaku Zasshi 6: 773-780 [in Japanese].

18. Kimata, H. 1933. Physiology of muscular exercise in animals. 9. Effects of exercise. Ouyo Juigaku Zasshi 6: 833-846 [in Japanese].
19. Matsuba, S., and Shimamura, T. 1933. Studies on exercise physiology and performance testing of the racehorse. The Imperial Racing Association [in Japanese].

20. Matsuba, S., Shimamura, T., Kimata, H., Shimazaki, Y., Kijima, T., and Shijo, T. 1938. Studies on the physiology of muscular exercise of the racehorse. I. The present method of training and its influence upon the physiology of the racehorse. J. Cent. Soc. Vet. Med. 51: 1-69 [in Japanese]. [CrossRef]

21. Matsuba, S., Shimamura, T., Kijima, T., and Shijo, T. 1938. Studies on the physiology of muscular exercise of the racehorse. II. On the influence of the conservative method of training upon the physiology of the racehorse. J. Cent. Soc. Vet. Med. 51: 187-347 [in Japanese]. [CrossRef]

22. Matsuba, S., Shimamura, T., and Shijo, T. 1938. Studies on the physiology of muscular exercise of the racehorse. III. On the influence of administration of various medicaments during the training (A). J. Cent. Soc. Vet. Med. 51: 585-641 [in Japanese]. [CrossRef]

23. Matsuba, S., Shimamura, T., and Shijo, T. 1938. Studies on the physiology of muscular exercise of the racehorse. III. On the influence of administration of various medicaments during the training (B). J. Cent. Soc. Vet. Med. 51: 659-728 [in Japanese]. [CrossRef]

24. Matsuba, S., Shimamura, T., Okabe, T., and Shijo, T. 1938. Studies on the physiology of muscular exercise of the racehorse. IV. On the physical change of the blood and its significance with regard to the control of training. J. Cent. Soc. Vet. Med. 51: 927-1058 [in Japanese]. [CrossRef]

25. Matsuba, S. 1939. Studies on the performance and training of the racehorse. The University of Tokyo [in Japanese].

26. Miyata, H., Sugiura, T., Kai, M., Hiraga, A., and Tokuriki, M. 1999. A field study of muscle adaptation to training on a flat or sloped track in Thoroughbred racehorses. Am. J. Vet. Res. 60: 1536-1539. [Medline]

27. Nomura, S., Senoo, T., Amada, A., Senta, T., Sawazaki, H., and Ibaraki, T. 1964. Radiotelemetric studies on electrocardiograms in horses and riders. 1. Performance of radiotelemeter. Exp. Rep. Equine Hlth. Lab. 2: 29-47 [in Japanese].

28. Nomura, S., Senoo, T., Amada, A., Senta, T., Sawazaki, H., and Ibaraki, T. 1964. Radiotelemetric studies on electrocardiograms in horses and riders. 2. Changes of electrocardiograms, heart rate and heart beat intervals during exercise. Exp. Rep. Equine Hlth. Lab. 2: 49-65 [in Japanese].

29. Nomura, S. 1964. New approaches for evaluating performance of draft horses by using heart beat. Series of equestrian affairs. 9. Japan Equine Affairs Association [in Japanese].

30. Numata, T., Sawayama, S., and Yasuda, S. 1931. On the influence of work on blood creatine content. Res. Rep. Jpn. Army Vet. Corps 261: 1-16 [in Japanese].

31. Ogura, K. 1942. Performance testing of the horse. Taiwan Chikusankai [in Japanese]. 
32. Ohmura, H., Hiraga, A., Matsui, A., Aida, H., Inoue, Y., Asai, Y., and Jones, J.H. 2002. Physiological responses of young Thoroughbreds during their first year of race training. Equine Vet. J. Suppl. 34: 140-146. [Medline] [CrossRef]

33. Ohmura, H., Hiraga, A., Matsui, A., Aida, H., Inoue, Y., Sakamoto, K., Tomita, M., and Asai, Y. 2002. Changes in running velocity at heart rate 200 beats/min (V200) in young thoroughbred horses undergoing conventional endurance training. Equine Vet. J. 34: 634-635. [Medline] [CrossRef]

34. Ohmura, H., Hiraga, A., Aida, H., Kuwahara, M., and Tsubone, H. 2002. Effects of initial handling and training on autonomic nervous function in young Thoroughbreds. Am. J. Vet. Res. 63: 1488-1491. [Medline] [CrossRef]

35. Okabe, T., and Sugiyama, T. 1944. On the respiration of horses during exercise, especially alteration of its frequency. Jpn. J. Vet. Sci. 6: 1-17 [in Japanese with German title and summary]. [CrossRef]

36. Okabe, T., Seto, Y., Miura, T., Nomura, S., Sawazaki, T., and Inada, S. 1954. Comparison of labouring power between horses and cattle: analysis of the walking in draught. I. On the vertical movement in various parts of body. Nihon Chikusan Gakkaiho 25: 174-178 [in Japanese]. [CrossRef]

37. Persson, S.G., Ekman, L., Lydin, G., and Tufvesson, G. 1973. Circulatory effects of splenectomy in the horse. I. Effect on red-cell distribution and variability of haematocrit in the peripheral blood. Zentralbl. Veterinarmed. A 20: 441-455. [Medline] [CrossRef]

38. Research division of Japanese Army Veterinary Academy. 1936. Effect of exercise on the physiological parameters. Res. Rep. Jpn. Army Vet. Corps 328: 1-31 [in Japanese].

39. Sakurai, N. 1941. Performance of the racehorse and its erythrocyte sedimentation rate. Jpn. J. Vet. Sci. 3: 651-661 [in Japanese with German title and summary]. [CrossRef]

40. Sakurai, N. 1943. On the performance of the racehorse and physical property of the blood. Chosa Kenkyu Hokoku 2: 27-44 (Research Reports).

41. Sakurai, N. 1951. Changes in clinical and blood characteristic findings in relation to training of the racehorse. Chosa Kenkyu Hokoku 4: 1-199 (Research Reports).

42. Sakurai, N., Uehara, N., Taguchi, K., and Tanabe, T. 1964.
Changes in blood characteristics with growth and training in the racehorse. Exp. Rep. Equine Hlth. Lab. 2: 167-170 [in Japanese].

43. Sakurai, N. 1971. Erythrocyte sedimentation rate; especially "erythrocyte sedimentation rate-body weight method" for evaluation of condition of racehorses. Equine Health Laboratory [in Japanese].

44. Sawayama, S. 1930. Exercise physiology of the warhorse. Res. Rep. Jpn. Army Vet. Corps 250: 1-150 [in Japanese].

45. Sawazaki, H. 1993. Equine science pioneers in Japan. Jpn. J. Equine Sci. 4: 123-135 [in Japanese with English summary]. [CrossRef]

46. Tatsumi, H., Chiba, H., Kato, M., Ueno, K., Okabe, T., Seto, Y., and Kano, Y. 1958. Studies on workload during labor force of animal farming: energy expenditure of the horse during pulling crop work. Nohgiken Hohkoku G. 14: 81-91 [in Japanese].

47. Tatsumi, H., Chiba, H., and Ueno, K. 1958. Effect of water depth on energy expenditure of horses during walk. Nohgiken Hohkoku G. 15: 27-33 [in Japanese].

48. Tatsumi, H., Kato, M., Chiba, H., and Okabe, T. 1959. Significance of pulse rate as an index of workload. Nohgiken Hohkoku G. 17: 59-66 [in Japanese].

49. Yamano, S., Eto, D., Sugiura, T., Kai, M., Hiraga, A., Tokuriki, M., and Miyata, H. 2002. Effect of growth and training on muscle adaptation in Thoroughbred horses. Am. J. Vet. Res. 63: 1408-1412. [Medline] [CrossRef]

50. Yamano, S., Eto, D., Kasashima, Y., Hiraga, A., Sugiura, T., and Miyata, H. 2005. Evaluation of developmental changes in the coexpression of myosin heavy chains and metabolic properties of equine skeletal muscle fibers. Am. J. Vet. Res. 66: 401-405. [Medline] [CrossRef]

51. Yasuda, S. 1930. Studies on blood glucose content of horses and the influence of work on it. Res. Rep. Jpn. Army Vet. Corps 253: 21-33 [in Japanese].

52. Yasuda, S. 1934. Studies on the influence of work upon the lactic acid content in the blood of horses. J. Cent. Soc. Vet. Med. 47: 449-457 [in Japanese]. [CrossRef]

53. Yasuda, S., Nitahara, H., and Ogihara, N. 1944. Studies on electrocardiography of the warhorse. J. Jpn. Vet. Med. Assoc. 1: 57-65, 109-117 [in Japanese]. 